\title{
Strategic Management in Zimbabwean Profit and Non-profit Organizations: Identifying the Missing Tools in the Strategy Implementation Kit Bag
}

\author{
Lysias Tapiwanashe Charumbira
}

Graduate School of Business, National University of Science and Technology, Zimbabwe

\begin{abstract}
The purpose of this study was to identify the determinants of strategic success or failure in Zimbabwean Profit and Non-Profit Organizations. The convergent parallel mixed methods research design was adopted as the guiding model for the data collection, analysis and interpretation process in this study. This explains why data was collected through a concurrent parallel methodological triangulation of questionnaires, semi-structured interviews, and document analysis. Quantitative data was analyzed using the Statistical Package for Social Sciences (SPSS) version 21.0 while the analysis of qualitative data was performed using the NVivo 10 data analysis software. The study established that there is a high rate of strategy implementation failure in Zimbabwean Profit and Non-profit Organizations. The failure to build the distinctive competences and resource capabilities needed for successful strategy implementation was identified as the main cause of strategic failure in these Organizations.
\end{abstract}

Keywords: Strategic Management, Environmental Scanning, Strategy Formulation, Strategy Implementation, Evaluation and Control, Strategic Success, Strategic Failure

\section{INTRODUCTION}

Strategic Management is set of long-term managerial moves that are designed to transform organizations to a sustainable desired future competitive state by enhancing their ability to minimize weaknesses and use their strengths to create defenses against competitive threats and capture the best growth opportunities in their operating environment. According to Wheelen and Hunger (2006) strategic management consists of four basic elements;

- Environmental Scanning-Where are we now?

- Strategy Formulation-Where do we want to go?

- Strategy Implementation- How do we get there?

- Evaluation and Control-Are we on course?

Thompson and Strickland (2003) note that although separate stages can be identified in the strategic management process, it is an on-going never-ending process, not a start-stop event that, once done, can be safely put aside for a while.

Environmental Scanning; is the analysis of the internal and external environment in order to identify the internal strengths upon which to base competitive strategies, the internal weakness that need to be corrected, the external growth opportunities that need to be captured, and the external threats that need to be defended against for sustainable competitive advantage. Environmental scanning is conducted through such tools as; the Strengths, Weaknesses, Opportunities, Threats(SWOT)Analysis, Polical, Economic,Sociocultural, Technological, Environmental, Legal (PESTEL)
Analysis, Value Chain Analysis, Task/industry Analysis and Strategic brand analysis, among others.

Strategy formulation; involves the crafting of:

- A statement that describes the organization's desired future state(Vision);

- A statement that describes the purpose of the organization, in terms of the products and services it provides to its customers(Mission);

- The shared timeless principles that guide the organization's members in the operations (Core Values);

- The critical skills and resources needed for an organization to satisfy customers and achieve its strategic goals(Key Success Factors);

- Open-ended statements summing up what the organization wishes achieve in each of the selected areas of strategic focus(Goal);

- Quantified and time-framed statements specifying the result of planned activity(Objectives);

- Actions through which organizations set to achieve their goals and objectives and reach its desired future state(Strategies);

- Policies that guide strategy implementation.

Strategy implementation; involves transforming plans into actions that drive the organization towards its desired future state. 
The last element, evaluation and control; is a process where planned strategic activities and their results are monitored by comparing actual performance with planned performance and using the resulting information to take corrective action.

Thus, strategic management is a diverse discipline with many different elements to investigate. It was however, beyond the scope of this study to investigate every aspect of strategic management. The study only focused on identifying the determinants of strategic success or failure in Zimbabwean profit and non-profit organisations. The decision to focus on strategy implementation was influenced by the realisation that there are low rates of strategy implementation success Zimbabwean profit and non-profit organizations. Similar trends were observed in other countries.

Charan (1999) notes nine out of ten organizations fail to implement their strategic plans due to their failure to implement internal strategies that are needed to transform them into strategy implementing organization by creating fits between strategy and organizational capabilities, reward structure, support systems and organizational culture . A review of strategic management literature recorded diverse views on the causes of failure in strategy implementation. Studies by Beer and Eisenstat (2000) identified laissez-fare senior management style, vague strategy, an ineffective senior management team, poor vertical communications, poor coordination across functions and inadequate low-level leadership skills and development as the six silent killers of strategy implementation. Alexander (1991); Galpin 1998; and Thompson and Strickland (2003) view weak management role, unfeasibility of the strategy, misunderstanding of the strategy, unaligned organizational systems and resources, lack of communication, lacking commitment to the strategy, poor coordination and sharing of responsibilities, inadequate capabilities and uncontrollable environmental factors as the main causes of failure in strategy implementation. In the same vein, $\mathrm{Li}$ Yang et al.(2008) reviewed sixty peer-reviewed journal articles on strategy implementation and identified the strategy formulation process, the strategy executors, organizational structures, communication activities, level of commitment towards the strategy, consensus regarding the strategy, relationships among different units or departments and different strategy levels, implementation tactics used and administrative system in place as the key factors that affect strategy implementation.

Aaker (1998) defines strategy implementation as the process that turns strategies and plans into actions in order to accomplish strategic objectives and goals. It involves the task of appropriately realigning an organization's structure, systems, leadership, culture, policies and management processes and associated activities in managing change required for translating the strategy into day to day activities (Ibid). These critical actions move a strategic plan from a document to actions that drive business growth, and this has failed for much organization. Implementing a strategic plan is as important, or even more important, than the strategy itself. Raps (2004) illustrates this by arguing that a strategic plan provides an organization with the roadmap it needs to pursue a specific strategic direction and set of performance goals, deliver customer value, and be successful. According to Raps (2004), a strategic plan is just a plan; it doesn't guarantee that the desired performance is reached. Having a roadmap does not guarantee the traveller's arrival at the desired destination(Ibid).Thompson and Strickland (2003), on the other hand, contend that strategy implementation entails building an organization capable of carrying out strategy successfully by:

- Establishing a strategy nurturing structure and culture. This entails building an organization with the distinctive competences and resource strengths to carry out the organizational strategy successfully.

- Staffing organizations with employees whose experience, technical skills, personalities, beliefs, and values match the brand's essence, promise and personality.

- Ensure that operations, systems and logistics support the delivery of the brand promise.

- Creating efficient and effective internal communication channels and uses them to communicate brand position, priorities, strategies, how each employee can execute that strategy, and how the organization and employees can benefit from the strategic management process.

- Establishing brand strategy-supportive policies and procedures.

- Allocating sufficient resources to strategy-critical activities.

- Instituting best practices and programs for continuous improvement.

- Installing support systems.

- Tying reward structure to achievement of strategic objectives.

It is important to note that strategic success depends on the ability to monitor and adapt to the changes in the organization's internal and external environment.

An analysis of strategic management literature published in the last twenty years revealed that most of the studies on strategy implementation were conducted in Europe, North America, Asia and Australia. The literature search failed to identify any published Zimbabwean academic studies on the subject. 
As a result, the nature and significance of strategy implementation in Zimbabwean Profit and Non-profit Organizations is opaque and remains under-researched. Very little is known about how it works. Therefore, one of the main limitations of the reviewed literature is that it may not accurately mirror the strategic management practices in Zimbabwe Profit and Non-profit Organizations since it is based on studies that were carried out in organizations that operate under economic, political, socio-cultural and technological conditions which are different from those prevailing in the country. These knowledge gaps influenced this researcher to carry out this study in a bid to develop an adapted strategy implementation framework for Zimbabwean organizations. The findings can also contribute towards the improvement of the strategic management process in the country through the identification of the measures that Zimbabwean Profit and Non-profit organizations need to adopt to ensure strategic success.

\section{Methodology}

The study was grounded on the convergent parallel mixed methods research design. According to Creswell and Plano Clark (2011), the convergent parallel mixed methods research design occurs when the researcher uses concurrent timing to implement the quantitative and qualitative strands during the same phase of the research process, prioritizes the methods equally, and keeps the strands independent during analysis and then mixes the results during the overall interpretation. In this study, quantitative data was collected by means of questionnaires while qualitative data was collected through semi-structured interviews and document analysis as shown in the Figure 1.

Questionnaires were used to collect from forty purposively sampled employees drawn from ten Zimbabwean Profit and Non-profit organizations. The size of the sample for the questionnaire survey was considered to be sufficient to represent and generalize to the research population with an acceptable level of confidence. This was informed by the views of Sekaran (1992, p 253) cites Roscoe (1975) who proposed that, as a rule of thumb for determining sample size; "sample sizes larger than 30 and less than 500 are appropriate for most research."

The use of questionnaires in this study was informed by the views of Bryman (2009) who notes their cheapness and quickness in terms of administration, the absence of the Interviewer effect and their convenience for correspondence as their main advantage. The use of questionnaires also enabled the collection of standardized information from the forty respondents.

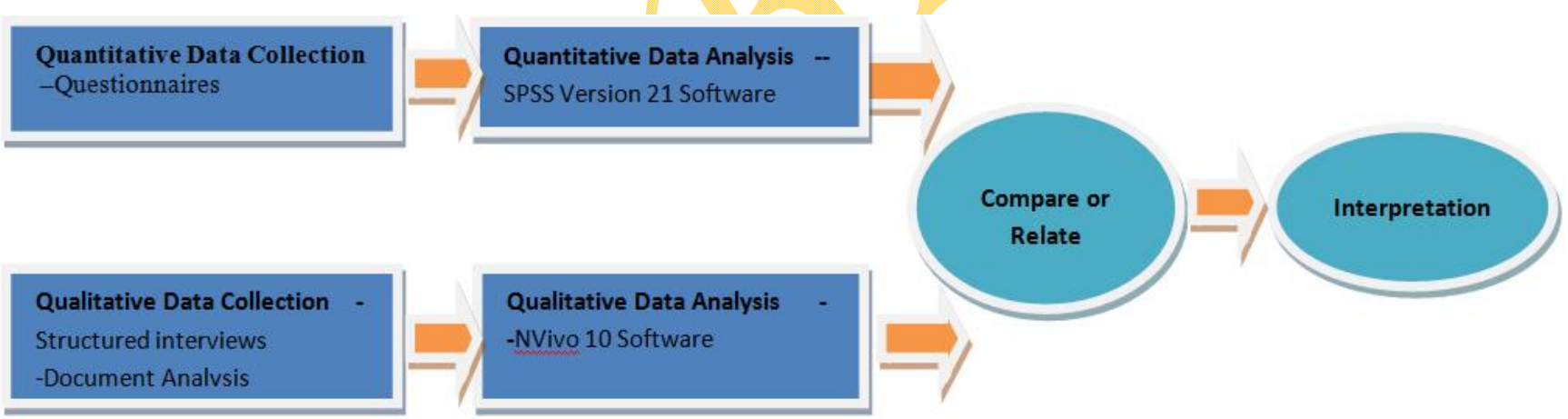

Figure 1: Adapted from Creswell and Plano Clark (2011).

Denscombe (1998) argues that questionnaires are best suited for collecting data on facts and opinions. This explains why they were used to extract employee opinions on the determinants of strategic success or failure in their respective organizations The decision to use questionnaire was also influenced by their ability to easily reach a geographically disparate sample population as by noted Neuman (2009), since the study covered the entire country.

Semi-structured interviews were used to gather data from ten managers drawn from the organizations that were selected to participate in the study. Their use was influenced by Denscombe (1998) who argues that interviews are used in cases where there have been no previous researches (as is the case with this study), to provide the detailed information needed to explore the nature of the problem. The selection of interviews was further encouraged by Freebody (2003) who notes that interviewing is a useful way of collecting qualitative data because the technique is introspective and allows respondents to report on themselves, their views, their beliefs, practices, interactions and concerns.

The Strategic plans of the ten organizations were also secured and analysed to complement data collected through questionnaires and semi-structured interviews. This is in line with the views of Noor (2008) who argue that documentary sources are used to supplement and compensate for the limitations of other methods.

According to Denzin (1989), no single method can completely capture all the relevant features of a research study. As a result, the mixing of qualitative and quantitative data collection techniques in this study sought to minimize the effects of the shortcomings each method on the quality of the study. Such an approach 
has the potential to strengthen the validity of the results (Edwards and Skinner, 2009). Bryman (2009) also notes that combining different methodologies in a single study enhances the researcher's claim for the validity of his or her conclusions if they can be shown to provide complementary results.

Quantitative data was analyzed using the Statistical Package for Social Sciences (SPSS) version 21.0. while the analysis of qualitative data was performed using the NVivo 10 data analysis software.

Ethical standards were adopted in this research through coding all participants' names and the name of the organizations they represent. This was meant to guarantee confidentiality and anonymity.

\section{REsults AND Discussions}

The semi-structured interview results showed that there is a high rate of strategy implementation failure in Zimbabwean profit and non-profit organizations. Forty percent of the interviewees attributed this high failure rate to the unstable economic environment in the country since the turn of the millennium. These results are almost consistent with the results from the questionnaire survey where fifty percent of the respondents attributed the high failure rate of strategy implementation failure in Zimbabwean profit and non-profit organizations to the distressed economic conditions in the country. The results are in line with the views of such scholars as Wheelen and Hunger (2006) and Thompson and Strickland (2003) who note that strategic planning is best suited for stable economic environments. As a result, it may not be responsive to such rapidly changing and complex environments as those prevailing in Zimbabwe since 2000. Sixty percent of the interviewees attributed the high rate of failure in strategy implementation to the implementing organizations' failure to build organizations the distinctive competence and resource strengths needed to carry out the organizational strategy successfully. In the same vein, fifty percent of the questionnaire survey participants attributed the high rate of failure in strategy implementation in Zimbabwean Profit and Non-profit organizations to the same factor.

The forty questionnaire survey participants were then asked to indicate the extent to which they agree with a set of internal branding status statements on a five-point Likertlike scale. The resultant low mean scores on most of the key determinants of strategic success validate the observation that strategic failure in Zimbabwean profit and non-profit organizations is mainly caused by failure to build organizations with the distinctive competences and resource strengths needed to carry out the organizational strategy successfully, as summarized in Table 1.

In the table:

- A mean score closer to 4 indicates that the survey participants strongly agree that factor under consideration is a significant determinant of strategic success in their organizations;

- A mean score closer to 3 indicates that the survey participants agree that factor under consideration is a significant determinant of strategic success in their organizations;

- A mean score closer to 2 indicates that the survey participants are neutral on whether the factor under consideration is a significant determinant of strategic success in their organizations;

- A mean score closer to 1 indicates that the survey participants disagree with the view that factor under consideration is a significant determinant of strategic success in their organizations;

- A mean score closer to 0 indicates that the survey participants strongly disagree with the view that factor under consideration is a significant determinant of strategic success in their organizations;

- Standard deviation shows the degree by which the responses deviate from the mean. A low score shows some convergence on the part of the respondent's view. A high score shows that the respondents' views on the subject under consideration vary significantly.

Thus, the mean score of 2 for feasibility of strategy shows that the majority of the respondents are not sure whether their organizations' strategies are feasible or not. According Vroom's (1964) Expectancy Theory of Motivation, people will exert a high effort if they believe that there is a reasonable probability that the effort will lead to the attainment of organizational goals. As a result, a situation where workers are not certain whether the organizational strategy is feasible or not is not conducive for successful strategy implementation

The study shows that only management employees are involved in the strategy formulation process in the ten case study companies. These results are inconsistent with the views of Li Yang et al. (2008) who note that the one of the most important determinant of strategy success is involvement of all stakeholders from strategy formulation process, right through to the implementation stages. According to Li Yang et al. (2008), the strategy formulation process should be widely communicated to everyone involved so that they all understand their roles and also own the strategy. Harrington (2006) also considers involvement of all as a significant determinant of strategy implementation success.

According to the Goal Setting Theory of Motivation by Locke and Latham (1990), employees are motivated to achieve goals they establish together with managers. As a result, the high rate of failure in strategy implementation efforts in Zimbabwean Profit and Non-profit Organizations can be attributed to the fact that the workers who were excluded from the strategic formulation process are not motivated to achieve the goals that were imposed on them by senior management. 
Asian Business Review, Volume 4, Number 3/2014 (Issue 9)

ISSN 2304-2613 (Print); ISSN 2305-8730 (Online)

The findings show that Zimbabwean Profit and Non-profit Organizations do not allocate adequate strategy supportive resources. Strategic failure in these organizations is therefore; consistent with the views of Downes (2001) who argues that some strategies fail because of failure to allocate adequate resources for successful implementation. Failure to allocate adequate strategy supportive resources is a bigger threat to capital intensive strategies (lbid).

Although employee rewards were not aligned to the attainment of strategic goals, performance appraisals were however based on the attainment of strategic goals. These results are consistent with the views of Davis (2000), Thompson and Strickland (2003), and VanAuken (2002) who argues that performance appraisals should always focus on assessing how well individuals and groups are delivering against the strategic objectives.

Li Yang et al. (2008) view employee commitment as one of the major determinants of strategy implementation success. This view is echoed by Hrebiniak (2006) who notes that strategy implementation demands employee commitment and passion for success. Thus, the low mean score rating of 0.83 recorded on employee commitment in this study shows that the levels of

employee commitment to strategy in Zimbabwean Profit and Non-profit Organizations are low and this has negative effects on the strategy implementation process.

The low mean scores for culture and structure show that Zimbabwean profit and non-profit organizations do not strive to create a strategy supportive organizational culture and structure before strategy implementation. These results are inconsistent with the views of Aaker and Joachimsthaler (2009), who argue that the key determinant of strategy implementation success is creating an organizational structure and processes that support strategy activities. This view is corroborated by Drazin and Howard (1984) who argue that culture creates the quality of the internal environment and determines the extent of cooperation, degree of dedication and depth of strategic thinking within an organization. They go on to say that incorrect culture can seriously affect strategy implementation. Thus the organization and its cultural values have to be unfrozen before change can occur. The cultural context should be set with the tone, pace and character that is conducive to the strategic changes that promote successful implementation (Raps, 2004).

Table 1: The Key Determinants of Strategic Success in Zimbabwean Profit and Non-profit Organizations

\begin{tabular}{|c|c|c|c|c|c|}
\hline & $\mathrm{N}$ & Minimum & Maximum & Mean & $\begin{array}{l}\text { Std. } \\
\text { Deviation }\end{array}$ \\
\hline The organisation's current strategy is feasible. & 40 & 0 & 4 & 2.00 & 1.281 \\
\hline There is good vertical communication of strategy across all the organization's functional units. & 40 & 0 & 4 & .90 & 1.008 \\
\hline $\begin{array}{l}\text { The organization deliberately recruits employees with skills and attributes needed for successful } \\
\text { strategy implementation. }\end{array}$ & 40 & 0 & 0 & .00 & .000 \\
\hline The organization formulates policies to guide and support the strategy implementation process. & 40 & 0 & 4 & 1.00 & 1.569 \\
\hline Employee rewards and incentives are aligned to the attainment of strategic goals. & 40 & 0 & 4 & .93 & .997 \\
\hline Performance appraisals are based on the attainment of strategic goals. & 40 & 3 & 4 & 3.43 & .501 \\
\hline Adequate resources are allocated to strategic activities. & 40 & 0 & 4 & 1.00 & 1.569 \\
\hline All employees are trained to enable them to understand the strategic management process. & 40 & 0 & 0 & .00 & .000 \\
\hline $\begin{array}{l}\text { Only management level employees are trained to enable them to understand the strategic } \\
\text { management process. }\end{array}$ & 40 & 3 & 4 & 3.95 & .221 \\
\hline Management ensure that service delivery is aligned to the organizational strategic direction. & 40 & 3 & 4 & 3.75 & .439 \\
\hline $\begin{array}{l}\text { A strategy supportive organizational culture and work environment is created before strategy } \\
\text { implementation. }\end{array}$ & 40 & 0 & 4 & .63 & 1.275 \\
\hline There is clarity as to who is responsible for strategic performance. & 40 & 0 & 1 & .05 & .221 \\
\hline Support systems are in place to enable strategy implementation. & 40 & 0 & 4 & 1.08 & 1.639 \\
\hline All employees are involved in the strategy formulation process. & 40 & 0 & 0 & .00 & .000 \\
\hline $\begin{array}{l}\text { The organization ensures continued strategic fit by effectively monitoring and evaluating strategy } \\
\text { implementation and making necessary strategic adjustments. }\end{array}$ & 40 & 0 & 4 & 1.50 & 1.240 \\
\hline $\begin{array}{l}\text { Strategic failure in my organization can be attributed to the prevailing unstable economic } \\
\text { environment in the country }\end{array}$ & 40 & 0 & 4 & 1.85 & 1.594 \\
\hline $\begin{array}{l}\text { Failure in strategy implementation to be due to my organization's failure to build the distinctive } \\
\text { competences and resource strengths needed to carry out the organizational strategy successfully. }\end{array}$ & 40 & 0 & 4 & 1.90 & 1.692 \\
\hline Valid N (listwise) & 40 & & & & \\
\hline
\end{tabular}

The organizational structure and decision flow processes should always follow the strategy being implemented (Schaap, 2006). Strategy supportive structure with clarity as to who is responsible for strategic performance is also crucial for strategic success. A review of strategic management literature on the subject revealed that bureaucratic structures are associated with high strategy implementation failure rates. In the same vein, Raps
(2004) notes that an incorrect organizational culture can seriously affect strategy implementation, and hence the failure by Zimbabwean profit and non-profit organizations to create a strategy supportive organizational culture and structure before strategy implementation can be viewed as one of the major causes of strategic failure in these organizations. 
Aligning the reward systems to strategic activities is yet another factor that influences implementation success. The study showed that employee rewards are not linked to the attainment of strategic goals in Zimbabwean Profit and Non-profit Organizations. Noble (1999) argues that the development of cross-functional skills should be rewarded before strategy implementation. Time and performance-based incentives for implementation teams should be developed while lessening traditional functional incentives. The implementation process can be managed by adjusting incentives as strategy and environmental conditions change while maximizing cross-functional performance by establishing visible and consistent cross-functional rewards for successful implementation efforts (Ibid).In this light, the high rate of strategic failure in Zimbabwean Profit and Non-profit Organizations can be attributed to their failure base employee rewards on the attainment of strategic goals.

These findings are contrary to the recommendations by Mintzberg and Quinn (1991) who emphasized training of all employees at all levels for strategic success. The study results show that only management employees are trained to enable them to understand the strategic management process in Zimbabwean Profit and Non-profit Organizations. Thus, failure to train employees at all levels for strategic success could be one the causes of strategic failure in Zimbabwean Profit and Non-profit Organizations. The results above show that organizations do not deliberately recruit employees with skills and attributes needed for successful strategy implementation. These findings are inconsistent with the views of such scholars as Davis (2000), Thompson and Strickland (2001), and Van Auken (2002) who argued that organizations should engage employees whose experience, technical skills, personalities, beliefs, and values match with the strategic focus.

The findings show that most Zimbabwean Profit and Non-profit Organizations do not formulate policies to guide and support the strategy implementation process. This might be one of the reasons why the studied organizations were failing to successfully implement their strategies. These results are also inconsistent with the views of Davis (2000), Thompson and Strickland (2001), and Van Auken (2002) who submitted that, to attain strategic success, organizations should have support systems that support strategic management roles.

\section{Conclusion \& ReCommendations}

The findings show ,that although the prevailing distressed economic environment has contributed towards the high rate of strategic failure in Zimbabwean Profit and Nonprofit Organizations, the missing tools in their strategy implementation tool kit is their failure to make internal strategic organizational adjustments in order to build the resource capabilities and distinctive competences needed to transform them into strategy implementing organizations .As a result ,the effectiveness of the strategic management process in these organizations can only improve if they can make such strategic adjustments as:

- Involving all stakeholders in strategy formulation;

- Training all employees in strategy management;

- Allocating adequate and timely resources to strategy supportive activities;

- Aligning employee remuneration to strategic goals;

- Improving communication on strategy;

- Formulating policies that support strategic activities;

- Improving employee commitment to the strategy;

- Creating a strategy supportive organizational structure and culture;

- Constantly monitoring and evaluating the changes in their internal and external environment and making relevant strategic adjustments.

These recommendations are consistent with the views of Davis (2000), Thompson and Strickland (2003), and VanAuken (2002), who note that organizations have to be restructured through organizing their business functions and processes and decision making in a manner that is conducive to successful strategy execution. The restructuring should also ensure that strategy implementation accountability is clear to all implementers.

\section{REFERENCES}

Aaker, D., 1998, Strategic Marketing Management, $5^{\text {th }}$ Edition, John Wiley and Sons Inc.

Aaker, D.A., and Joachimsthaler, E., 2009, Brand Leadership, Free Press New York.

Alexander, L. D., 1991, Strategy Implementation: Nature of the Problem, International Review of Strategic Management 2(1)

Anderson, G., 1993, Fundamentals of Educational Research.Falmer Press, London, and pp: 152-160.

Beer M., \& Eisenstat R. A., 2000, The Silent Killers of Strategy Implementation and Learning, Sloan Management Review, 41 (4)

Bryman, A., 2009, Social Research Methods ( $3^{\text {rd }}$ edition) London, SAGE Publications Ltd.

Buchanan, B., 1974, Building Organizational Commitment-The Socialization of Managers in Work Organizations, Administrative Science Quarterly, 19(4).

Charan, R., 1999, Business Builders, management solutions, exponential results, Fortunes Journal.

Creswell, J. W. and Plano Clark, V. L., 2011, Designing and Conducting Mixed Methods Research. Thousand Oaks, CA: Sage.

Creswell, J.W., 2003, Research Design: Qualitative, Quantitative and Mixed Methods Approaches, 2nd edition, SAGE, London.

Davis, S.M., 2000, Brand Asset Management: Driving Profitable Growth through Your Brands, Jossey-Bass Inc Publishers, a Francisco, and California.

Denscombe M., 1998, the Good Research Guide for Small Scale Social Research Projects. Glasgow, MacGraw Hill.

Denscombe, M., (2010) the Good Research Guide for Small Social Research Projects, Glasgow, McGraw-Hill House.

Denzin, N. K., 1989, the Research Act. A Theoretical Introduction to Sociological Methods (3rd Ed). New Jersey, Prentice Hall. 
Downes, L., 2001, Strategy Can be Deadly-Industry Trend or Event, the Industry Standard.

Drazin,R. And Howard, P, 1984, Strategy Implementation: A Techniques for Organizational Design, Columbia Journal of World Business, 19:40-46.

Edwards, A. and Skinner, J., 2009, Qualitative Research in Sports Management, Elsevier Ltd, Hungary.

Freebody, P. 2003. Qualitative Research in Education: Interaction and Practice, London, Sage Press.

Galpin J. T., 1998, When Leaders Really Walk the Talk: Making Strategy Work Through People, Human Resource Planning, 21 (3).

Harrington, R. J., 2006, The Moderating Effects of Size, Manager Tactics and Involvement on Strategy Implementation in Food Service, Hospitality Management, 25(3):385-395.

Hrebiniak, L.G., 2006, Obstacles to Effective Strategy Implementation. Organizational Dynamics 35(1): 12-31.

Li Yang, Guohui, S. And Eppler, M. J., 2008. Making Strategy Work: A Literature Review on the Factors Influencing Strategy Implementation,ICA Working Paper.

Locke, E.P., and Latham, G.P, 1990, a Theory of Goal Setting and Task Performance. Upper Saddle River, NJ: Prentice Hall.

Mintzberg, H. and Quinn, J. B., 1991, The Strategy Process: Concepts, Contexts, Cases, Second edition, Englewood Cliffs, NJ, Prentice Hall.

Neuman C.,2009, Designing Social Research (6 ${ }^{\text {th }}$ edition) London Blackwell Publishing

Noble, C. H., 1999, the Eclectic Roots of Strategy Implementation Research, Journal of Business Research, $45,119-134$.
Noor,K.B.M,2008, Case Study: A Strategic Research Methodology, American Journal of Applied Sciences 5 (11): 1602-1604

Raps, A., 2004, Implementing Strategy - Tap Into the Power of Four Key Factors to Deliver Success.

Saunders, M., Lewis, P. and Thornhill A., 2007, Research Methods for Business Students, Pitman Publishing, London.

Schaap, J.I., 2006, Toward Strategy Implementation Success: An Empirical Study of the Role of Senior- Level Leaders in the Nevada Gaming Industry. UNLV Gaming Research \& Review, 10: 13-37.

Sekaran, U., 1992, Research Methods of Business: A SkillBuilding Approach (2nd ed.). New York, USA: John Wiley and Sons, Inc.

Sharma, A., 2009, Implementing Balanced Scorecard for Performance Measurement, The Icfai University Press.

Thompson A.A. ,Strickland A.J and Gambles ,J.E.,2003, Crafting and Executing strategy, McGraw-Hill,

VanAuken, B., 2002 the Brand Management Checklist, Kogan Page LTD, London, UK.

Vroom, Victor H., 1964, Work and Motivation. John Wiley \& Sons, Inc. Abstract: Vroom's seminal book that introduces his Expectancy Theory Cognitive Model. Vroom Introduces the Model and its Concepts of Valence, Expectancy, and Force

Wheelen, T.L. and Hunger, D.J., 2006, Strategic Management and Business Policy, Prentice Hall, New Jersey, USA.

Yin, R. K., 2003, Case Study Research, Design and Methods, 3rd ed. Newbury Park, Sage Publications.

Yin, R.K., 1994, Case Study Research: Design and Methods, Sage Publication, Thousands Oakes, California.

\section{How to Cite}

Charumbira LT. 2014. Strategic Management in Zimbabwean Profit and Non-profit Organizations: Identifying the Missing Tools in the Strategy Implementation Kit Bag Asian Business Review, 4, 7-13. 